\title{
"Self-sacrifice" as accidental outcome of extreme within-group mutualism
}

\author{
Antoine Marie*
}

*PhD Student, Center for Research and Interdisciplinarity (CRI), Paris, France

\section{Introduction}

Phenomena of apparent "self-sacrifice" and experiences of selflessly giving one's life for one's group or a transcendental mission probably represent the epitome of dynamics of radicalization and military combat. Evidence suggests they are typically facilitated by proximate processes of identity fusion with comrades (Whitehouse 2018) and communion in the sacralization of the group's cause (e.g. "the Kalifate", "the Reich"; Atran 2010).

\section{Main argument}

Departing from frameworks holding that the ultimate function of "sacrificial" behaviors is altruistic-incurring absolute individual costs to benefit others-I argue that at least some of the behaviors we call self-sacrifical may be parsimoniously explained as the outcomes of the activation of mutualistic, i.e. interdependence-based propensities to take extreme risks for comrades in exchange for their protection, which would accidentally lead to death. These would have evolved by classical, gene-level selection through partner choice mechanisms taking place within ancestral coalitions in contexts of integroup warfare.

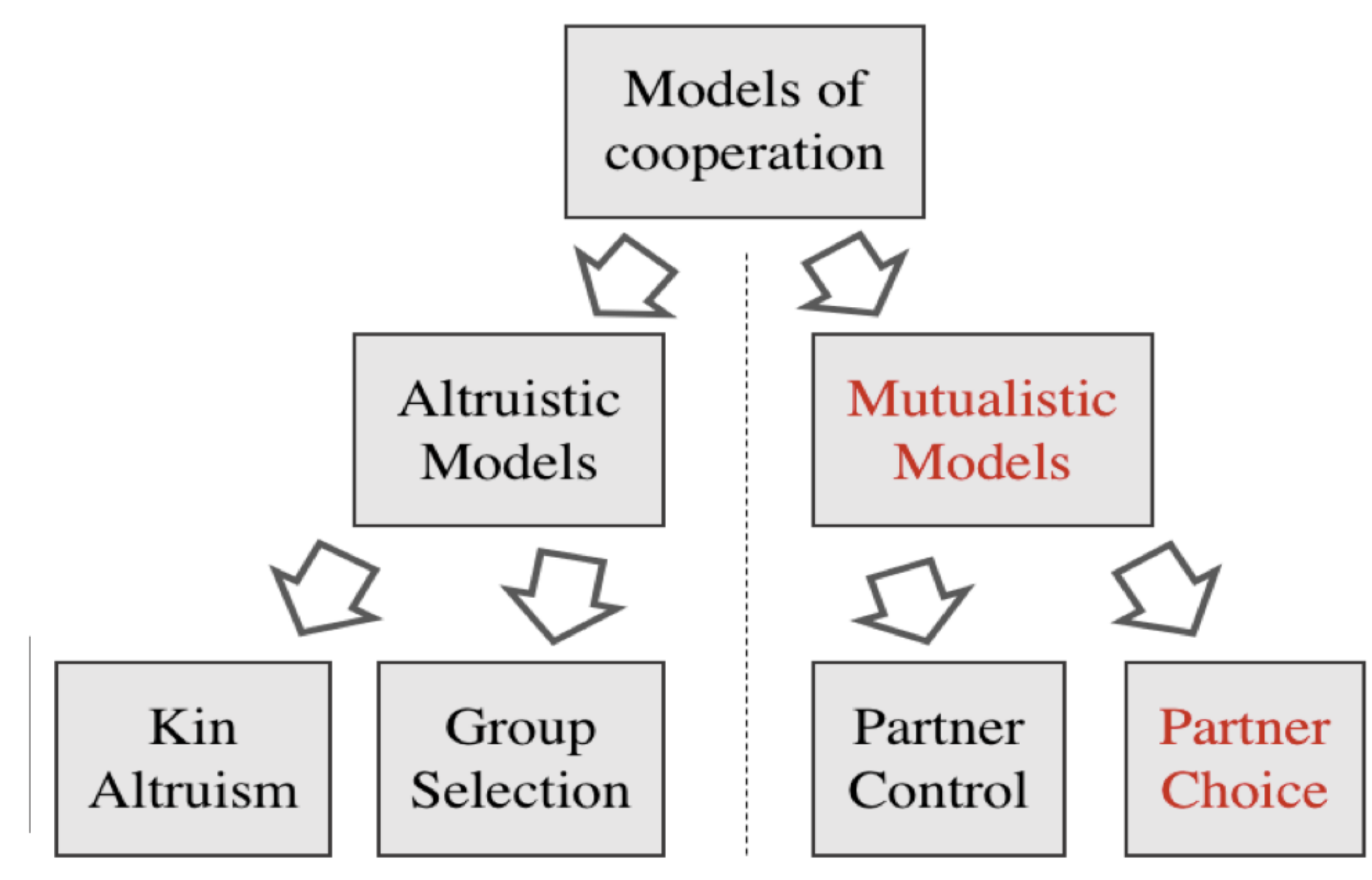

From partner choice and mutualism to a genuine sense of fairness (Baumard et al. 2013).

evolutionary mechanisms:



$B$ is free to shun A and prefer D

if B's return on investment is

greater when bargaining with D psychological outcome: a

genuine sense of fairness biological function:

\section{Behaviors and computations:}

Unconscious bookkeeping of:

- others' contributions and retributions

- cooperativeness and freeriding

- one's dependence on one's partners

Phenomenology \&

emotions:

- Genuine concern for others' interests

- aversion to cheating
- Securing fitness benefits via joint ventures

- Enhancing one's reputation as a trustworthy partner
The cooperation market of standard partner choice models is quite atomistic. However, consider that the ancestral competition for resources and the advent of weapons operated at a distance (like spears) sustained intergroup warfare, which in turn would have selected for dispositions to form increasingly cohesive coalitions (which enhance total formidability while reducing individual risk [Tooby \& Cosmides 2010]).

Second, recall that coalitions are n-party exchanges: even when it involves a dozen fighters reciprocating help and protection, a coalitional alliance obeys the same partner choice mutualistic logic as other joint ventures.

Third, the high lethality of ancestral raids suggested by paleoanthropology (LeBlanc \& Register 2003) would have radically increased the degree to which individual fitness within coalitions was mediated by protection from partners (e.g., compensating for dead angles). Given these parameters, and provided that extreme interdependence was recurrent enough over evolutionary time, partner choice mechanisms within groups may have selected for dispositions for equally extreme individual heroism as the best way of securing vital protection from one's comrades, independently of genetic relatedness.

Death on the battlefield would only be an accidental outcome, resulting from the misfiring of these adaptations - from risk miscalculations by the inference systems involved.

From partner choice and mutualism to extreme parochially altruistic, apparently "sacrificial" behavior.

evolutionary mechanisms:

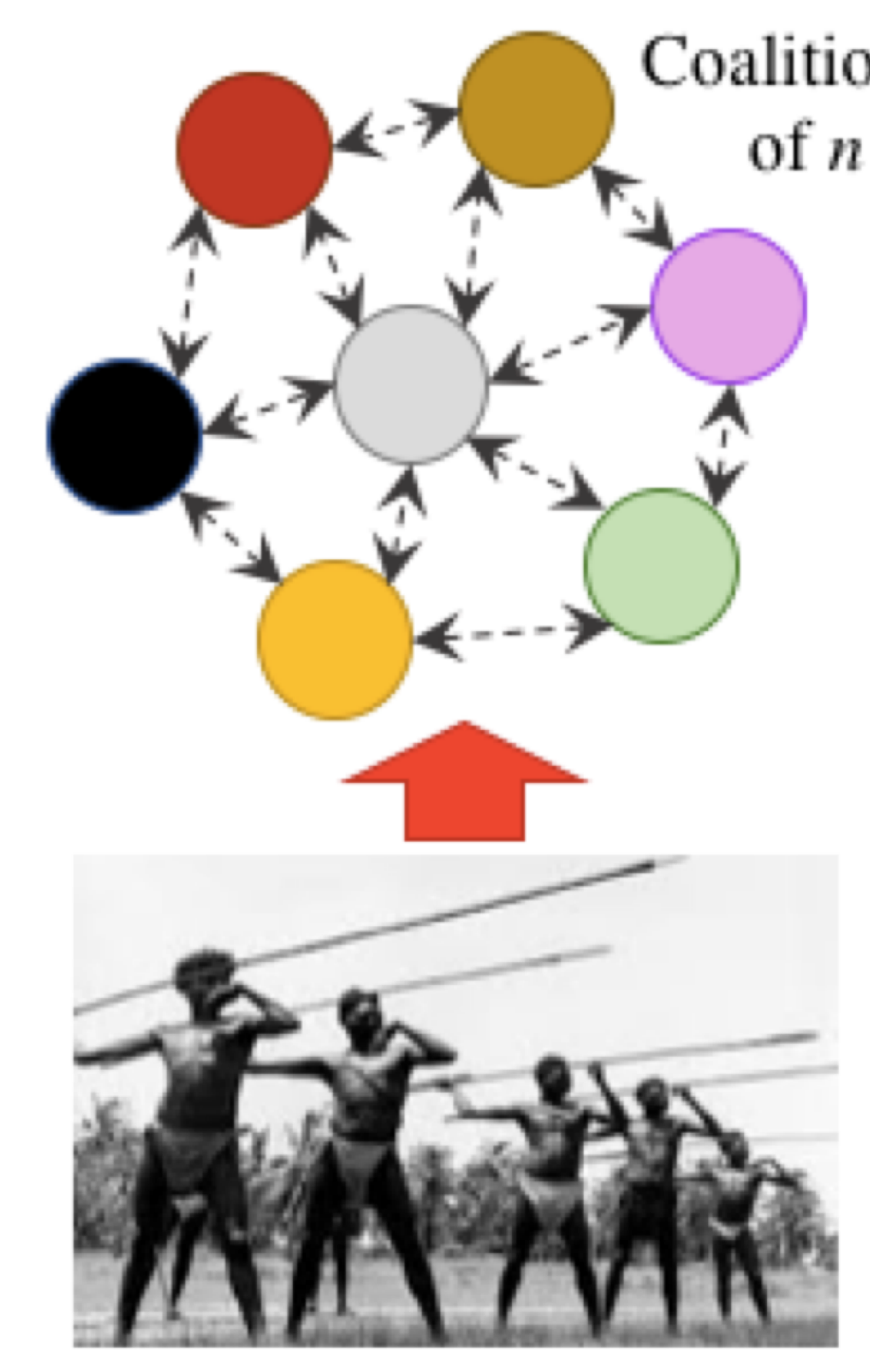

Coalitional alliance $n$ fighters psychological outcome: extreme commitment

biological function:

Behaviors:

Heroic acts protecting

(deserving) comrades in

proportion to one's

interdependence on them

Phenomenology \& emotions:

- Sense of "sacrificing" for comrades

- Experiences of identity fusion

- Dispositions to sacralize the coalition's engagement

A rival coalition the coalition's engagenc betrayers
Securing help from comrades/ reputation enhancement

Not sacrifice

Death as accidental outcome 